\title{
O Professor de Medicina da UFSM no Contexto do Mal-Estar Docente
}

\author{
Dissatisfaction among Medical School \\ Faculty at the Federal University in Santa \\ Maria, Brazil
}

Olmiro Cezimbra de Souza Filho

Maria Inês Naujorks

\section{PALAVRASCHAVE:}

-Educação Médica;

- Docente de Medicina.

KEY-WORDS:

- Education, Medical;

- Faculty, Medical.

Recebido em: 25/11/2003

Reencamintrado em: 27/07/2004

Reencarninhado em: 03/12/2004

Aprovadoem:06/12/2004

JREVITTA BRLSTERRA DEEDUCA CIOMEDICA

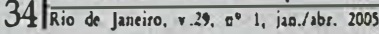

'Professor Assistente, Mestre em Educaçdo pelo PPCE - UFSM, Departamento de Morfologia, Centro de Ciéncias da Saúde, Universidade Federal de Santa Maria (UFSM). Santa Maria, Rio Grande do Sul, Brasil.

${ }^{2}$ Professora Doutora, Programa de Pós-Graduaçdo em Educaçūo, Centro de Educaçăo, Universidade Federal de Santa Maria (UFSM), Sants Maria, Rio Grande do Sul, Brasil. 


\section{INTRODUÇĀO}

O universo profissional médico apresenta características peculiares, próprias da sua formação acadêmica, de tal sorte que o indivíduo comprometido com seus conceitos mais cartesianos, ao defrontar-se com novas vivências, necessita desenvolver habilidades que lhe permitam construir um referencial muito mais amplo, no qual os sentimentos possam transitar com naturalidade, e os processos cognitivos ganhem nova dimensão.

O exercício da docência poderá gerar muitos questionamentos na mente dos professores. Sentir que falta substâncin diante de um contingente de alunos que expressa suas necessidades de saber e de conviver poderá ser um dos fatores geradores de mal-estar. Enquanto busca respostas dentro da sua necessidade pedagógica, o professor poderá perceber uma lacuna a ser discutida. Assim, surgem indagações do tipo: "Como se forma o professor médico?", "Existem no curriculo do curso de Medicina disciplinas que contemplem este aspecto?". Essas interrogações geram mal-estar e, então, perguntase: como este sujeito trabalha com tal sentimento? Convém salientar que aspectos relacionados à atividade médica também são geradores de mal-estar, o que poderia resultar em interações com a atitude docente.

A busca de respostas a esses questionamentos contribuiu para a realização do presente estudo, que se insere na linha de pesquisa de Formação de Professores, abordando a temática do mal-estar docente em professores da área médica.

Em relação à história de vida do professor médico, é possível perceber, desde sua vivência acadêmica, pontos de referência, nos quais professores com didńticas das mais variadas desfilaram neste palco, montado com objetivos muito específicos dentro da chamada medicina curativa, na qual a racionalidade é soberana - inclusive com frases proferidas com muita pompa, do tipo "um bom cirurgião necessita ser frio e racional!", ou seja, não pode se permitir expressar sentimentos. Por outro lado, este mesmo indivíduo deveria ter a capacidade de, ao entrar na sala de aula, deixar o cirurgiño do lado de fora e transformar-se no professor, como se isso fosse possível, quer dizer, uma fragmentação do eu. A partir dessa constatação, muitos momentos de falta ou falha de comunicação do binômio professor-aluno podem ser analisados.

A construção do conhecimento requer competências que não são inatas e, portanto, precisam ser arquitetadas dentro de uma realidade biopsicossocial, na qual é impossível desprezar qualquer aspecto que esteja ancorado nesse contexto. A habilidade do professor em reconhecer tal situação só será possível se ele possuir esse tipo de vivência em suas aquisi-

"Palaura inglesa que pode ser trmfuzida para o portuguts como "exanstino". ções experienciais. A tendência postural e o desenvolvimento da ação docente a partir de um modelo limitado e repetitivo ocorrem justamente porque se acredita, de forma reducionista, que, para ser um bom professor, basta ter a formação profissional, ainda que esta seja muito boa.

Um aspecto interessante e potencializador do fenômeno de burnout ' no caso do professor médico é que, além de sua questionável formação pedagógica, ainda necessitaria lidar com situações de estresse do dia-a-dia, inerentes à profissão iátrica, fato que remete a um leque de novos questionamentos passiveis de discussão.

Considerando-se que o mal-estar pode estar presente na atividade tanto médica, como docente, o sujeito poderia vivenciar de forma exponencial e circular esse sentimento, criando um mecanismo de realimentação com conseqüências imprevisíveis. Procurar entender essa engrenagem intrincada de coexistência como profissional médico e profissional docente que habitam o mesmo sujeito permite trabalhar com múltiplos enfoques, em que o prisma axiológico poderá mostrar inúmeras figuras de representação.

De acordo com Isaia!, "na busca de suporte teórico para nossa investigação sobre os sentimentos que permeiam a docência universitária, voltamo-nos para autores que, apesar de divergências, são unânimes em afirmar a necessidade de um estudo unitário do professor". Trabalhar com aspectos de relação interpessoal e elaborações intrapessoais na construção do conhecimento, independentemente da área do saber, abre um campo muito vasto de interpretações, o que justifica a variedade de opiniões sobre o assunto.

Perceber a necessidade de respostas, bem como as limitações existentes, gera angústia, e é neste ponto que se opta pela acomodação, ou, ao contrário, aceita-se o desafio de buscar amarras em outros referenciais do saber. Essa realidade deu origem ao presente estudo, que busca discutir os questionamentos que envolvem a formação docente médica e o mal-estar do professor médico da Universidade Federal de Santa Maria - RS (UFSM).

Este estudo teve como objetivo pesquisar, no grupo de professores médicos do Centro de Ciências da Saúde do curso de Medicina da UFSM, a existência de indicadores relacionados ao mal-estar docente. No universo de 94 docentes que preenchiam os pré-requisitos para participar do estudo - ser efetivo há pelo menos cinco anos e estar em atividade docente -, 16 não foram localizados para a entrega do questionário; dos 78 restantes, 44 retornaram o instrumento de pesquisa.

\section{METODOLOGIA}

A abordagem utilizada neste estudo, de cunho quantitativo e descritivo, foi realizada por meio de um instrumento 
elaborado por Jesus², adaptado à gramática brasileira e validado pelo referido autor, intitulado "Instrumento para avaliação das variáveis que constituem indicadores do bem $/ \mathrm{mal}$ estar docente". Trata-se de um questionário fechado, com 113 questões, no qual é utilizada a escala do tipo Likert.

A análise dos dados foi efetivada de acordo com as regras para cotação e interpretação propostas pelo mesmo autor.

A proposta desta pesquisa foi submetida à apreciação do Comitê de Ética em Pesquisa do CCS/UFSM (registrado no Conep: ne 175), tendo obtido parecer favorável (096/03).

\section{RESULTADOS}

\section{Dados demográficos}

A amostra deste estudo é composta de 33 (75\%) docentes do sexo masculino e 11 (25\%) do sexo feminino. Essa predominância é também citada por Batista ${ }^{3}$ ao analisar a pesquisa do Cinaem-97. Isso pode ser interpretado como conseqüência da realidade de décadas passadas, em que os bancos da escola médica eram preenchidos em sua grande maioria por homens.

Com relação à idade e ao tempo de serviço, dois professores não responderam ao primeiro quesito, enquanto três não o fizeram em relação ao segundo. É interessante observar que a idade mínima foi de 37 anos, e a média em torno de 48 anos, considerada por Mosquera e Stobäus ${ }^{4}$ como a adultez média. Nessa fase, sentimentos diversos relacionados tanto aos sucessos quanto às frustrações poderiam se manifestar, pois, ao mesmo tempo em que os sujeitos já possuem uma bagagem experiencial, defrontam-se com situações próprias da faixa etária da citada segunda fase existencial da vida adulta. Por vezes, torna-se necessário reconsiderar conceitos que já tinham como pétreos $e$, frente às novas exigências, como comentam Esteve ${ }^{5}$, Schön6 e Pérez Gómez 7 , precisam reconstruir habilidades que julgavam suficientes para desempenhar suas funções profissionais. Manifestações relacionadas a distúrbios da saúde também poderão se fazer presentes, gerando um somatório adverso para esses indivíduos. Para os docentes do gênero feminino, os sintomas do climatério (menopausa) poderão concorrer para aumentar o mal-estar. Nessa época, ainda ocorrem rompimentos de determinados vínculos afetivos, como a saida dos filhos de casa.

A faixa etária apresentada pelo professorado deste estudo reflete a política dos últimos anos de governo, com a não contratação de professores efetivos. Essa constatação é corroborada pela média do tempo de serviço, em torno de 19 anos, que é a fase do questionamento, do balanço profissional. Segundo Huberman ${ }^{8}$, esse é um período em que o professor reavalia os ideais e objetivos do início da carreira, dado que também deve ser considerado como um aval (experiência) para as de- mais respostas do instrumento, pois o tempo mínimo de serviço foi de seis anos.

Quanto ao estado civil, a grande maioria dos professores médicos (79\%) mantém um vínculo estável ao se declararem casados. Apenas dois eram solteiros e cinco separados. Dois professores não responderam a esse quesito. Esses dados podem refletir considerações sobre os aspectos da vida familiar e a referida fase do questionamento citada por Huberman ${ }^{8}$. A situação de estabilidade familiar pode significar um componente social importante na atuação profissional, já que, no convívio familiar, experimentam-se constantemente situações dialógicas por vezes conflituosas, alternadas com momentos de afetividade. Não raro, ouvem-se professores dirigindo-se à classe como meus filhos, e essa paternidade poderá ser permeada por atuações muito semelhantes às que acontecem no seio familiar.

Ao se observar a situação profissional, é possível verificar que mais da metade dos professores que responderam a esse quesito já atingiu a progressão de adjunto ou titular. Este é mais um dado para se somar à maturidade da amostra, embora não se possa considerar somente o fator de progressão como significante de maturidade, pois, de acordo com Mosquera ${ }^{9}$, para se chegar à chamada personalidade madura, é necessária uma construção social elaborada a partir de uma série de características que contemplem as expectativas da coletividade. É evidente que o nivel de progressão tem peso importante nesse sentido. Aqui convém citar que 17 professores não responderam adequadamente a esse quesito, referindo outras situações de cunho médico.

No item relacionado ao nivel de formação, é interessante observar que a maior parte $(75 \%)$ permaneceu no nível de especialização, muitas vezes adquirido antes da carreira docente. Isso pode significar um paradoxo em relação ao exposto no quesito anterior. Por outro lado, deve-se considerar que, num passado recente, não era exigida titulação para se galgarem niveis superiores; bastava o tempo de serviço, por exemplo.

É necessário colocar em pauta também a falta de estímulo das instituições no sentido de proporcionar estudos de pósgraduação e a pouca disponibilidade de tempo para esse fim por parte dos professores médicos, muitos dos quais, por vezes, exercem a atividade assistencial em vários empregos, conforme expõem Lampert ${ }^{10}$ e Batista ${ }^{3}$. Em sua grande maioria, não são apresentadas sequer condições logísticas para um bom desempenho profissional, nem se cogita a possibilidade de liberar o empregado para cursos de aperfeiçoamento, pois o único e primordial objetivo é o lucro.

É pertinente salientar que todos os departamentos nos quais atuam professores médicos que ministram aulas para o 
curso de Medicina se fizeram representar, evitando uma homogenia da amostra.

Quanto às disciplinas pelas quais os professores da amostra são responsáveis, é possível de notar uma plêiade interessante (32), sendo que três não resp

\section{Dados referentes à análise comparativa das variáveis}

Esta seção apresenta uma análise comparativa das variáveis que constituem indicadores do bem/mal-estar docente, iniciando-se pela comparação entre as médias de referência ${ }^{2} \mathrm{e}$ as decorrentes da interpretação do questionário deste estudo (Tabela 1).

De acordo com as regras para cotação e interpretação das respostas ao instrumento de avaliação das variáveis ${ }^{2}$, os indicadores de mal-estar se farão presentes quando a média encontrada for inferior à de referência ${ }^{2}$ com relação a projeto profissional, empenho profissional, valor das metas, motivação intrínseca, expectativa de eficácia, expectativa de controle, atribuição causal, sucesso profissional e motivação inicial, e superior em relação às medidas de estresse, exaustão, crenças irracionais e estratégias de coping.

\section{Análise dos indicadores de mal-estar docente}

No quesito que trata do projeto profissional, o docente expõe sua intenção de continuar como professor ou exercer outra atividade, ou seja, demonstra seu desejo profissional atual ou futuro. Neste quesito, a média encontrada neste estudo $(4,048)$, comparativamente à média de referência ${ }^{2}(4,413)$, su- gere a existência de indicadores de mal-estar. Fatores relacionados à depreciação social do professor ${ }^{11,12}$ poderiam explicar tal constatação. Aqui pode ser aventado um sem-número de motivos que corroboram esse achado, que vão desde a lacuna formativa ${ }^{3,13}$, passam pelas novas exigências sociais e falta de apoio institucional, e chegam até a baixa remuneração $0^{5.14-17}$.

O valor das metas profissionais reflete a interação do professor com os alunos, na qual o aspecto interpessoal ganha destaque, revelando a real preocupação do professor com a aprendizagem e, conseqüentemente, com a formação dos alunos, bem como um ambiente perpassado pela afetividade ${ }^{18}$, quando é colocado que o professor poderá evitar o vínculo afetivo na tentativa de impedir seu próprio sofrimento quando o círculo de relação se desfizer.

Nesse momento, cabe buscar a idéia do profissional frio e calculista, por muito tempo almejada por aqueles que consideravam esta qualidade inerente ao bom médico, o qual não poderia se permitir externar suas emoções, sob pena de isto ser traduzido como fraqueza. Esse fato poderia levar à crise de identidade ${ }^{19}$. Levando-se em conta a faixa etária média do grupo deste estudo e seu período de formação profissional, isto poderia explicar a presença de mal-estar neste quesito.

Os dados referentes à expectativa de eficácia se reportam à capacidade de mediação do educador em relação ao ensino e à aprendizagem, na busca de créditos para o método utilizado. Ao se analisar a média dos docentes avaliados $(29,364)$, percebe-se que ela é inferior à média de referência ${ }^{2}(29,517)$, inferindo-se a existência de indicadores de mal-estar.

TABELA 1

Comparativo entre as médias referidas por Jesus ${ }^{2}$ e as decorrentes da interpretação do questionário deste estudo ("presença de indicadores de mal-estar)

\begin{tabular}{|c|c|c|}
\hline Variáveis & Média (Jesus²) & Média (deste estudo) \\
\hline 1. Avaliação do projeto profissional & 4,413 & 44,048 \\
\hline 2. Avaliaçāo do empenho profissional & 62,874 & 63,114 \\
\hline 3. Avaliaçāo do valor das metas vrofissionais & 30,615 & $+30,023$ \\
\hline 4. Avaliação da motivação intrínseca & 22,462 & 23,795 \\
\hline 5. Avaliaçāo da exvectativa de eficácia & 29,517 & $* 29,364$ \\
\hline 6. Avaliação da expectativa de controle & 44,846 & $* 44,223$ \\
\hline 7. Avaliação das atribuiç̧ōes causais A, de sucessos, segundo a dimensāo locus & 22,500 & 22,682 \\
\hline 7. Avaliaçāo das atribuiçōes causais $B$, de fracassos, segundo a dimensão locus & 16,300 & ${ }^{*} 14,591$ \\
\hline 7. Avaliação das atribuiçōes causais $C$, de sucessos, segundo a dimensão estabilidade & 16,300 & 16,454 \\
\hline 7. Avaliaçāo das atribuiçōes causais $D$, de fracassos, segundo a dimensāo estabilidade & 11,400 & $+10,932$ \\
\hline 8. Avaliaçāo do estresse profissional & 317,594 & 166,136 \\
\hline 9. Avaliação da exaustão profissional & 428,783 & 183,207 \\
\hline 10. Avaliaçāo das crenças irracionais & 39,09 & 37,318 \\
\hline 11. Avaliação das estratégias de coning (resolução de problemas) & 23,568 & ${ }^{\star} 24,932$ \\
\hline 12. Avaliação do sucesso profissional & 26,943 & 29,204 \\
\hline 13. Avaliaçāo da motivaçāo inicial para a profissāo docente & 26,757 & ${ }^{*} 20,886$ \\
\hline
\end{tabular}


Convém, assim, buscar a questão do vazio pedagógico do professor de Medicina ${ }^{3.13}$. A ausência, no currículo do curso médico, de disciplinas que contemplem esse aspecto é uma realidade que permanece até os dias atuais.

A mesma situação ocorreu com relação à expectativa de controle, em que a média deste estudo $(44,223)$ foi menor que a média de referência ${ }^{2}$, indicando mal-estar. Essa variável abrange os sentimentos que o professor experimenta em relação não apenas ao seu empenho na busca do reconhecimento da sua atuação pedagógica, mas também às suas dúvidas quanto ao sentimento que os alunos guardam em relação às suas aulas.

Frente aos novos desafios que se descortinam para o professorado $3,5,6,20,21,22$, seja no plano tecnológico, seja no plano social, o educadornecessita reciclar-se continuamente. No caso do professor médico, principalmente quando este é atuante também no campo assistencial, essa necessidade é uma realidade vivida desde os bancos da escola. No entanto, nem sempre essa vivência acontece em sua atuação docente.

Nos resultados obtidos pelos professores, sejam eles desejados (sucessos) ou não (fracassos), relacionados às atribuições causais seja na dimensão locus, seja na dimensão estabilidade, somente os índices relacionados aos fracassos $(14,591 \mathrm{e}$ 10,932 , respectivamente) ficaram abaixo da média de referên$\operatorname{cia}^{2}(16,300$ e 11,400$)$. Ou seja, ao experimentar as situações que resultam em fracassos, o grupo desta pesquisa demonstra indicadores de mal-estar.

A profissão médica, na formação tradicional13, não trabalha com as situações de insucesso com a devida consideração que elas demandam. Na verdade, muito pelo contrário, a formação médica valoriza de forma exorbitante o sucesso (verdadeira onipotência) e se esquece de trabalhar de forma adequada com os resultados indesejados. Por isso, os sujeitos que não tiveram formação didática específica nos bancos da universidade atuam no enfrentamento das situações adversas no ambiente pedagógico utilizando a mesma carga simbólica concebida na escola médica.

Trabalhar com os sentimentos e desenvolver uma postura humanística são novos rumos que as comissões envolvidas com a reestruturação dos currículos dos cursos de Medicina no Brasil pretendem implementar,30,23.

Em relação ao item que abrange as estratégias de coping, ou seja, a busca da resolução de problemas objetivando lidar com os fatores de estresse que concorrem para o mal-estar, os professores estudados apresentaram uma média $(24,932)$ acima da média de referência ${ }^{2}(23,568)$, demonstrando a necessidade de utilização das estratégias frente aos fatores geradores de estresse.
TABELA 2

Percentual de professores acima e abaixo da média na avaliaçāo da motivação inicial para a profissāo docente

\begin{tabular}{c|c|c|c}
\hline Soma dos itens & $N^{2}$ de professores & $\begin{array}{c}N^{2} \text { de professores } \\
\text { acumulado }\end{array}$ & Percentual \\
\hline 15 & 2 & 2 & \\
\hline 17 & 3 & 5 & \\
\hline 18 & 4 & 9 & \\
\hline 19 & 2 & 11 & \multirow{2}{*}{$\begin{array}{c}\text { da média } \\
\text { da abaixo }\end{array}$} \\
\hline 20 & 8 & 19 & \\
\hline 21 & 6 & 25 & \\
\hline 22 & 4 & 29 & \\
\hline 23 & 7 & 36 & \\
\hline 24 & 7 & 43 & \\
\hline 25 & 1 & &
\end{tabular}

Ao lidar com as situações clínicas, o médico, desde a sua formação acadêmica, necessita desenvolver habilidades que lhe permitam desvendar diagnósticos. Porém, a sensibilidade para enfrentar situações adversas no âmbito pedagógico só se fará presente se outros fatores independentes do currículo concorrerem para isto ${ }^{3}$.

A avaliação da motivação inicial para a profissão docente, que abrange a escolha pelo ensino, a vontade de ser professor como escolha profissional inicial, demonstrou e confirmou algo que dificilmente seria diferente: $100 \%$ dos analisados ficaram abaixo da média de referência ${ }^{2}(26,757)$, conforme demonstra a Tabela 2 .

Essa declaração explícita de que ser professor foi obra do acaso e não fruto do desejo pode ser analisada, a princípio, com base numa constatação já discutida no decorrer deste estudo - a carência curricular -, porque o currículo do curso de Medicina não oferta nenhuma disciplina que tenha sequer uma conotação pedagógica ${ }^{13}$. Nlém disso, a depreciação social do professor, também citada neste trabalho, dificilmente faria com que um vestibulando se inscrevesse no concurso vestibular para um curso extremamente disputado, no qual a relação candidato/vaga é altissima, com o objetivo de ser docente.

\section{CONSIDERAÇŌES FINAIS}

A temática que abarca o mal-estar docente ébastante atual e trata-se de uma preocupação mundial'12. Portanto, investigar a existência de indicadores nos professores médicos do curso de Medicina da UFSM permite conhecer um pouco melhor os sentimentos que permeiam essa comunidade e instigar novas pesquisas, mais abrangentes e complementadas por um viés qualitativo. 
O alicerce didático não é contemplado no currículo médico, sendo visto como uma habilidade inata. Essa visão distorcida, por mais incrivel que pareça, permanece nos dias atuais.

A importância de pesquisas que analisam a situação docente médica é indiscutível, pois tais pesquisas poderão servir como pedra fundamental para a construção de um novo profissional da Educação Médica, para que a formação não seja negligenciada, até mesmo em respeito a uma sociedade que investe, e muito, e que espera, no mínimo, um retorno de qualidade para a coletividade.

Muito do mal-estar poderá ter origem na lacuna da formação pedagógica, quando o indivíduo, de repente, só percebe o fato quando já está contratado, respondendo por uma ou mais disciplinas. Então, poderá se perguntar: "Ei, quem disse que eu sou professor?".

Lidar com o comportamento muitas vezes inadequado dos alunos não é uma ação simples e fácil, pois requer competências e habilidades que certamente não foram aprendidas nos bancos da escola médica. O enfrentamento da indisciplina requer uma sensibilidade que só pode ser concebida por quem aprendeu a aprender. Não se trata de simplesmente lançar mão da representação do antigo professor e, de maneira repetitiva, agir de forma agressiva ou ameaçadora, do tipo "esperem para ver a avaliação de vocês!". Ao usar esse tipo de expediente, o professor irá alimentar um círculo vicioso de mútuas agressões e extremamente estressante para todos. Ao contrário, se houvesse aprendido a interagir com qualidade, certamente o ambiente seria outro.

Romper com a formação médica tradicional, que nem sequer prevê a possibilidade de que o aluno de Medicina tenha pretensões para a docência ou, mesmo depois de formado, deseje ser professor, é uma ação positiva que deve ser considerada por todos os que tratam do assunto.

Essa situação também é denunciada quando se analisam os resultados relativos ao projeto profissional e ao valor das metas profissionais do grupo estudado, que, apresentando indicadores de mal-estar, poderiam ser entendidos como o desejo de abandonar a profissão docente. Isso poderia ser explicado, em parte, pela deficiência na formação, não permitindo um compromisso futuro, uma implicação sedimentada.

Embora percebam sua deficiência formativa e a entrada para a docência de maneira não planejada, conforme atesta o item sobre a motivação inicial, os indivíduos gostam de se sentir professores e empenham-se para isso, como demonstram as outras variáveis.

As variáveis referentes às atribuições causais revelaram, como não poderia ser diferente, que o professor médico se defronta com o mal-estar ao experimentar os fracassos, sejam estes atribuídos aos motivos oriundos da sua própria pessoa ou percebidos como oriundos do ambiente de aula. Novamente, é necessário retornar à mesma questão: se a pessoa não desenvolveu, durante sua formação profissional, habilidades mediadas por sentimentos socialmente construídos junto a pessoas mais maduras e com vivência pedagógica, não terá substância para resolver determinadas adversidades.

Deve-se levar em conta, também, que, além dos aspectos peculiares ao professor médico, os demais fatores relacionados como desencadeadores do mal-estar docente para o professorado em geral, independentemente de ter havido ou não formação pedagógica, vêm se somar aos denunciados anteriormente. Assim, as novas exigências do saber-fazer também concorrem para o mal-estar do docente médico.

Aqui é possivel analisar outra faceta que também pode explicar a motivação intrínseca: a sensação de status que o título de professor pode causar, pois, não raramente, lê-se em receituários médicos que determinado profissional é professor em tal ou qual especialidade. Dessa forma, percebe-se com clareza a distinção específica pelo fato de ter galgado tal posição institucional, estimada pelo próprio indivíduo, que, por vezes, a bem da verdade, nem mereceria ser chamado de professor.

Assim, acredito que toda contribuição embasada em pesquisa que possa colaborar para criar uma ação mais humana em qualquer nível de ensino, certamente, terá seu retorno social validado, e poderá o genuíno professor declarar: "hoje sou um ser humano melhor do que ontem".

Este estudo não guarda a pretensão de esgotar um assunto tão complexo como o mal-estar na docência médica, que envolve vários aspectos importantes e a revisão de inúmeros autores. Cultiva, porém, a esperança de que outros pesquisadores igualmente se interessem pelo assunto, de tal forma que as vozes e as atitudes irão, aos poucos, quem sabe, formando a vontade de transformar.

\section{REFERÊNCIAS}

1. Isaia SMA. Os sentimentos como dinamizadores da prática pedagógica universitária: sua relação com a produção e a docência. Caesura. jan./jun. 1996; p. 3-9.

2. Jesus SN. A motivação para a profissão docente. Contributo para a clarificação de situações de mal-estar e para a fundamentação de estratégias de formação de professores. Aveiro: Estante, 1996a.

3. Batista NA. Formação do professor de medicina: desafios e perspectivas. In: Marcondes E, Lima-Gonçalves, E. Educação médica. São Paulo: Sarvier; 1998.

4. Mosquera JJM, Stobäus CD. Educação para a saúde; desafio para sociedades em mudança. 2. ed. Porto Alegre (RS): D.C. Luzzatto; 1984. 
5. Esteve J. Mudanças sociais e função docente. In: Nóvoa A, org. Profissão professor. Porto (RS): Porto Editora; 1991.

6. Schön DA. Formar professores como profissionais reflexivos. In: Nóvoa A, org. Os professores e a sua formação. Lisboa: Dom Quixote; 1992.

7. Pérez Gómez AI. A cultura escolar na sociedade neoliberal. Porto Alegre: ARTMED; 2001.

8. Huberman M. La vie des enseignants: évolution et bilan d'une profession. Paris: Delachaux et Niestlé; 1989.

9. Mosquera JJM. Psicodinâmica do aprender. Porto Alegre (RS): Sulina; 1975.

10. Lampert JB. Tendências de mudanças na formação médica no Brasil: tipologia das escolas. São Paulo: Hucitec-ABEM, 2002.

11. Esteve J. O mal-estar docente - a sala de aula e a saúde dos professores. Bauru (SP): EDUSC, 1999.

12. Mosquera JJM, Stobäus CD. O mal-estar na docência: causas e conseqüências. Revista da ADPPUCRS nov. 2000; (2): p. 23-34.

13. Castro CLM, Silva FAA, Ghivelder M. O professor de medicina. Rio de Janeiro: UFRJ; 1969.

14. Demo P. Desafios modernos da educação. Petrópolis (RJ): Vozes; 1993.

15. Demo P. Educação e qualidade. Petrópolis (RJ): Vozes; 1994.

16. Perrenoud P. Construir as competências desde a escola. Porto Alegre (RS): Artes Médicas; 1999.
17. Perrenoud P. Novas competências para ensinar. Porto Alegre (RS): Artes Médicas; 2000.

18. Codo W, Gazzotti AA. Trabalho e afetividade. In: Codo W, coord. Educação: carinho e trabalho. Petrópolis (RJ): Vozes; 1999.

19. Batista AS, Codo W. Crise de identidade e sofrimento. In Codo W, coord. Educação: carinho e trabalho. Petrópolis (RJ): Vozes; 1999.

20. Loureiro WN, org. Formação e profissionalização docente. Goiânia: UFG, 1999.

21. Enricone D, org. Ser professor. 2. ed. Porto Alegre (RS): EDIPUCRS; 2002.

22. Pimenta SG, Ghedin E, orgs. Professor reflexivo no Brasil: gênese e crítica de um conceito. 2. ed. São Paulo: Cortez; 2002.

23. Boulos M. Relação médico-paciente: o ponto de vista do clínico. In: Marcondes E, Gonçalves EL. Educação médica. São Paulo: Sarvier; 1998.

\section{Endereço para correspondência}

Olmiro Cezimbra de Souza Filho Rua do Acampamento, 569 - Centro 97050-003 - Santa Maria - RS e-mail: ocesfilho@simers.net

Maria Inês Naujorks

Residencial Alto da Colina, Rua 2, 135 - Camobi

97110-620 - Santa Maria - RS

e-mail: minau@terra.com.br 